\title{
EARTHQUAKE ENGINEERING
}


This page is intentionally left blank 


\title{
EARTHQUAKE ENGINEERING
}

Mechanism, Damage Assessment and Structural Design

\author{
S. F. Borg \\ Professor of Civil Engineering \\ Stevens Institute of Technology \\ Hoboken, New Jersey, USA
}

(Second \& Revised Edition) 
Published by

World Scientific Publishing Co. Pte. Ltd.

P. O. Box 128, Farrer Road, Singapore 9128

U. S. A. office: World Scientific Publishing Co., Inc.

687 Hartwell Street, Teaneck NJ 07666, USA

\section{EARTHQUAKE ENGINEERING - (Second \& Revised Edition)}

Copyright 1988 by World Scientific Publishing Co Pte Ltd.

All rights reserved. This book, or parts thereof, may not be reproduced in any form or by any means, electronic or mechanical, including photocopying, reconding or any information stonage and retrieval system now known or to be invented, without written permission from the Publisher.

ISBN $9971-50-435-9$

Printed in Singapore by General Printing Services Pte. Ltd. 
This book is for

Audrey and Rebecca Lynne

and for

Daniel 
This page is intentionally left blank 


\section{PREFACE AND INTRODUCTION TO THE SECOND EDITION}

This book is an expanded version of the earlier (first edition) text, Earthquake Engineering - Damage Assessment and Structural Design, here called EE-DA\&SD. Every chapter of the first edition has been altered and enlarged and new chapters have been added to include work done by the author and some of his graduate students, following publication of $E E-D A \& S D$.

Some remarks concerning the modus operandi of the two texts may be in order.

In accordance with currently accepted methods of scientific inquiry, the procedures used in EE-DA\&SD and in this book for developing the rational earthquake engineering theory are as follows:

1. Key experiments are performed and quantitative data from these are collected. (In the earthquake engineering field there are two basic sets of quantitative experimental data - (a), the accelerogram record and (b) the isoseismal contour chart).

2. Generalized relations (as simple and straightforward as possible) are looked for to describe the quantitative data of (1a) and (1b) above. The relations or equations or charts or invariants are given in terms of specifically earthquake engineering parameters - i.e., variables that are characteristic of earthquake engineering phenomena and very likely apply only to these phenomena. (It will be seen that such parameters and such invariants and resulting relations are, in fact, the bases for the rational theory of the text).

3. In addition to generalizing the experimental behaviour of (1) above, the relations should predict new quantitative results that may be verified experimentally. (It will be seen that a number of new quantitative relations are predicted using the new rational theory and these can be checked either in the field or in laboratories). 
The coverage of $E E-D A \& S D$ included the entire earthquake event starting with the onset of the earthquake (the mechanism), then proceeding to the transmission of earthquake energy to the ground surface, then the damage assessment and finally the structural design.

The fundamental point of view of $E E-D A \& S D$ (and also of the present text) is that energy is the most important parameter of the entire earthquake happening. Energy is released by some underground mechanism (and this is the earthquake), energy causes the damage to structures and energy is the basic input in the structural design process.

Secondly, as noted earlier, it was accepted as a given fact that two basic sources of quantitative experimental (i.e. field) data were available and these are the foundations upon which the rational theory of earthquake engineering must be built.

The two sets of experimental data were:

a) The accelerogram which, physically, must be related in some way to the variation, with time, of the ground energy at a point on the surface of the earth in the earthquake field.

b) The isoseismal contour map which, physically, must be related in some way to the variation, with distance, of the ground energy over the entire surface of the earth affected by the earthquake.

The rational quantitative theories of EE-DA\&SD were developed along three lines:

1. A closed-form mathematical solution for a theoretical mechanism was obtained, based upon a similarity solution for a plate rupture instability and an assumed underground superplastic-type material.

2. and 3. The accelerogram records and isoseismal maps referred to in (a) and (b) above were woven into a unified, comprehensive theory of energy transmission - timewise and spacewise - over the surface of the earthquake field.

The theory was then extended to include the major problems of damage assessment and structural design, both of which are developed in terms of the previously introduced isoseismal and accelerogram invariants and parameters. Various special topics related to these were also considered, including a brief discussion of model testing.

The present edition includes a postulated computation for an actual earthquake field, based upon a recent comprehensive geological test program, which can be related directly to the theoretical rupture instability mechanism. Because this analysis was not included in EE-DA\&SD and because the author feels that 
the rupture instability mechanism now has some physical justification for its derivational form, it was decided to expand the sub-title of the text. Hence, as indicated, the inclusion of the word Mechanism more completely describes the scope of the material contained herein.

One additional concept which is of fundamental importance in establishing a rational quantitative theory of earthquake engineering is the assumption of 'averageness' or the 'average condition'. Thus assumption lies at the base of all the various theories included in the comprehensive treatment presented - including the rupture instability mechanism. An especially illuminating discussion of this 'averageness' requirement occurs in Chapter 10, Section $E$ in which the anomalous behaviours of the very destructive September 19, 1985 Mexican earthquake are directly related to this characteristic property. The application presented there emphasizes the important effect of deviating from averageness on the magnification or diminution of earthquake damage and how this relates, quantitatively and rationally, to the energy approach of this text.

Indeed, the key words in describing the intended coverage of the earlier and present texts are rational and quantitative. It was taken for granted that engineers deal with numbers. Qualitative materials, if these were to be included, were of secondary and only supportive importance. The basic requirement was that numbers must be generated in all phases of the theory and applications.

Furthermore, the theories must be rational. Certainly some reliance was and will continue to be placed upon engineering and physical intuitive considerations. But in all cases these must be reasonable and must lead to testable results that could be used by and would be of value to the average well-trained professional in the earthquake engineering field - including engineers, architects, code and specification writers and insurance and related workers.

The crucible for the definitive testing of theories and predictions in earthquake engineering is the earthquake itself. Some portions of a theory and posssibly its predictions may perhaps be tested in laboratories and suggestions along these lines are included in later chapters of the book. But the difficulties of duplicating the required ground and energy absorption conditions of actual full size structures would seem to introduce problems related to model-prototype scaling that leave open to serious doubts the pertinence of the data generated by laboratory tests of reduced-size models.

A principal testing and checking procedure used in this text is the after-thefact analyses and comparisons between results predicted by the derived rational theory and those actually obtained due to earthquakes. Furthermore, because an earthquake is one of nature's more traumatic experiences and because the perceptions of the physical and human damage done by an earthquake are quick. ly altered by the healing affects of time, the major sources of some actual earth- 
quake damage data used in this text were the on-the-spot reports prepared by responsible professional major news gathering services all over the world. In effect, it was assumed that a description of the human and physical response prepared by reporters at the scene within hours after the onset of an earthquake, when this is available, is at least as reliable as that reported by a committee of observers who visit the site and question the inhabitants days and perhaps weeks after the actual event.

Wherever possible the results and predictions of the new theory were tested against quantitative earthquake data. Also, as was pointed out in EE-DA\&SD, an essential step in the application of the theory is the calibration of various fundamental (and uniquely earthquake engineering) parameters. This is an ongoing process, quite common in all fields of engineering (although few of these encounter the evaluation difficulties of earthquake engineering) and work along these lines forms a part of the extension of materials included herein.

There is no doubt whatever in the author's mind that as more and more data are collected, the various equations, design charts and other engineering tools derived here will become more accurate, thereby enabling engineers and the other earthquake engineering professionals to use the theories with greater accuracy and confidence.

However, by the same token, the author suggests that even at this point, the new rational quantitative theories can be applied by these same professionals, subject to an awareness of the approximations involved in the applications. As most practicing engineers realize, approximations - some small and some large - occur in all engineering designs and analyses.

The author takes this opportunity to thank several of his graduate students who prepared reports on various aspects of the overall earthquake engineering problem using the rational methods described in this book. Some of these reports contained data and results that extend and expand the coverage of $E E-D A \& S D$. Acknowledgement of this assistance is made at the appropriate points in the text. 


\section{CONTENTS}

Preface and Introduction to the Second Edition

Chapter 1 A Tensile Rupture Instability Similarity Earthquake Mechanism

Chapter 2 The Canonical Accelerogram and Its Parameters

Chapter 3 The Canonical Isoseismal Chart and Its Parameters

Chapter 4 The Earthquake Engineering Damage Assessement and Structural Design Charts and Curves

A) The Temporal Variation of Energy at a Point

B) The Spacewise Variation of Energy Over the Entire Field

C) The Magnitude $-\Sigma(I S)_{f}-S_{f}-$ Geology Chart

D) The Magnitude-Intensity-Distance (MID) Chart

E) The Intensity $-\Sigma(a \Delta t)_{f}-t_{f}-$ Geology Chart

F) The Energy -Intensity Compatibility Relation

Chapter 5 Efficiency-Focal Depth and Figure 4.5

Chapter 6 Superposition of Canonical Accelerograms

Chapter 7 Superposition of Canonical Isoseismal Contour Maps

Chapter 8 Approximate Analytical Damage (Intensity Number) Assessment Procedures 
Chapter 9 Special Topics in Earthquake Structural Engineering

A) Equivalent or Effective Length and Equivalent or Effective Base Area

B) Length-of-Time Effect for Tall Buildings

C) Damping of Vibrational Building Oscillations Due to an Earthquake

D) Model Scaling Requirements

Chapter 10 Some Non-Structural Applications of the Rational Theory

A) An Approximate Theoretical Predicted Isoseismal Map for the Predicted $M=6$ Parkfield Earthquake of 1988

B) The Earthquake-Code Zone of Bangladesh - A Comparison Analysis

C) An Approximate Theoretical Method for Analyzing Rock Slope Stability Due to Earthquakes

D) The Mexican Earthquake of September 19, 1985

191

E) Monitoring Underground Atomic Blasts

Chapter 11 Some Structural Applications of the Rational Theory

A) The Earthquake Engineering Analysis of the Supports for an Offshore Platform Structure (OPS)

B) The Earthquake Engineering Analysis of a Building with an Open, Ground Level, Column-

Supported Parking Area

C) The Earthquake Engineering Analysis of a Short Squat Shear-Type Structure $l / w<1 / 2$

D) The Earthquake Engineering Analysis of a Low to Intermediate Height Beam-Girder-Column Energy Absorbing Structure

E) The Earthquake Engineering Analysis of a High Structure, $\ell / w \simeq 5$

F) A Concrete Dam Earthquake Analysis 